\title{
How Does COVID -19 Affect Thai Students?
}

\author{
Prapattra Hongwisat $^{\mathrm{a}}$, Thanawat Wuthikanokkan ${ }^{\mathrm{a}}$, Chirati Romayes ${ }^{\mathrm{b}}$ \\ ${ }^{\text {a }}$ Sarasas Witaed Saimai School, Bangkok, 10220, Thailand \\ ${ }^{\mathrm{b}}$ Srinakharinwirot University Prasarnmit Demonstration School, Bangkok, 10110, Thailand
}

Corresponding Author: Prapattra Hongwisat

\begin{abstract}
This research was a study about the problem regarding unfavorable learning environments and stressful situations of Thai students during online studying amidst the COVID -19 situation and the solutions to improve the efficiency in learning and development for each age group. This research is an exploratory study of secondary to high school students in Thailand in 2021. The researcher interviewed 144 people in Thailand to obtain information regarding the problems, their effects, opinions, and possible solutions. They collected the data from the questionnaire and analyze the data to find more solutions to the problem. The data analyst used the frequency percentage statistic.

The results showed that 1.) Most students want to go to school due to a more comfortable learning environment compared to sitting at home with an unconducive learning environment. Further, learning at school allows students to ask their teachers immediately and the school includes the activities which help support and develop different students 2.). Most of the students will understand if they study diligently, on the other hand, some answered that they will not understand even if they study diligently due to various environmental factors, such as the unconducive environment for learning, 3.) Students have reasons for their problems; this is one of the causes of stress in online learning. Most reasons cite unsuitable environments and unstable online learning systems that make studying boring and inconsistent instruction. 4.) Thai students in the Covid-19 situation concern about their academic performance as old grading standards are still in use, and many said they got low grades. 5.) Out of 144 students, 81 students stated that they have a suitable home environment for online learning; while 63 students do not have a
\end{abstract}

suitable environment for learning due to various home factors like problems with internet instability and parents in the house who had them run errands during the course. In conclusion, the most common problem in online learning is problems with the learning environment.

Keywords: Students, Learning, COVID-19, Thailand

\section{INTRODUCTION}

The pandemic situation of the COVID-19 virus first occurred in Wuhan, Hubei Province, China. Afterward, It has spread to nearby countries where Thailand is one of the countries experiencing the COVID-19 outbreak. The virus causes various symptoms such as fever, shortness of breath, and affecting the respiratory system. Moreover, It can be spread from person to person through coughing, sneezing, or coming into contact with a patient's secretions (Jiraporn Sricham, 2020).

The situation of this virus also affects the overall economy and society. As a result, people in Thailand have to change their lifestyles, including the change of Thai education adapted to the form of online learning instead of going to school to reduce infection cases. Moreover, the spread of the virus to risk groups is reduced due to the distribution of pathogens

Currently, Thailand is still affected by the pandemic situation, causing many students to experience stress from assignments, exams, and activities. In addition, this research collected the 
responses of 144 students, using a questionnaire to ask opinions of Thai students from lower secondary to the high school level. The respondents were asked how they solved the problem and how they dealt with this problem. Based on the study, we are aware of the problems in online studying among students in Thailand during the COVID-19 situation and we want to lead to further solutions.

\section{METHODOLOGY}

The questionnaire surveys were used to collect data from 144 lower secondary to high school students in Thailand in the academic year 2021, asking questions regards to how COVID-19 affects Thai students to find both problems and impact to fix their problems. The researcher posed the following questions to analyze the data and bring different solutions. The questions divide into two parts. The first part looks like an itemized exam and the questions are the current grade level, the course of study, what form they are studying now, how students understood the class, the stress level encountered, Are grades worse or better compared to last year? Is the home environment suitable for studying? What kind of learning style did students prefer? Why?, problems encountered during online learning, How to solve problems encountered? For example, the question is What format are you studying now, online or onsite? 143 out of 144 Thai students responded that they studied online. Only one student studied at school.

\section{RESULT}

The result was a total of 144 respondents answered the questionnaire regarding the COVID-19 impact such as How does it affect Thai students? The 144 respondents were divided into grade levels in descending order: Mattayomsuksa 6, 63 people, Mathayom 4, 30 people, Mathayom 2, 17 people, Mattayom 3, 14 people, Mathayom 5, 11 people, and Mathayom 1, 9 people. It seems that most of the respondents were high school students.
Notably, in some schools, there are lines of study divided according to the preferences of the students which they can choose according to the faculty of the university they want to enter. It separates into ScienceMath, 72 students, Arts-Computing, 22 students, Arts-Language, 21 students, and 29 students in the lower secondary school who did not choose any major. However, 143 students in Thailand have studied online, only 1 person attended school onsite.

Table 1: Which type of study did students like more?
\begin{tabular}{|l|l|l|}
\hline Choice & Frequently & Percentage \\
\hline School & 132 & 91.67 \\
\hline Online & 7 & 4.86 \\
\hline Both school and online & 3 & 2.08 \\
\hline Neither school nor online & 2 & 1.39 \\
\hline
\end{tabular}

Table 1 shows that out of 144 respondents, only 7 people like online learning (4.86\%), 132 people like to study at school $(91.61 \%), 3$ people prefer both schools and online $(2.08 \%)$, and 2 chose neither school nor online (1.39\%). Apparently, most students prefer to go to school. The reason may be due to the conveniency in the school which differ compared to study at home as the atmosphere at home is not suitable for studying. While learning in school helps students since students can ask their teacher immediately and engage in activities that can help support and develop in terms of learning. For instance, doing a lab. And yet, some students answered that online learning is beneficial because it has options to playback the lecture via video. Aside from that, some students stated that both are suitable.

Table 2: Understanding during online learning
\begin{tabular}{|l|l|l|}
\hline Choice & Frequently & Percentage \\
\hline Don't understand & 15 & 10.4 \\
\hline Understand a little & 33 & 22.9 \\
\hline Understand if study hard & 76 & 52.8 \\
\hline Study hard but don't understand & 17 & 11.8 \\
\hline Very understand & 3 & 2.1 \\
\hline
\end{tabular}

Table 2 shows that most students chose the answer, understand if study hard, which represents 52.8 percent, follows by, understand a little, accounts for $22.9 \%$, then $11.8 \%$ of students chose, study hard but don't understand, next, $10.4 \%$ said they do 
not understand, and lastly, $2.1 \%$ chose very understand. Based on the data, it seems that most students would understand if they study hard. On the other hand, some stated that even if they studied hard, they would not understand due to various environmental factors like an unconducive environment for learning.

Table 3: Study stress level

\begin{tabular}{|c|c|c|}
\hline choice & Frequently & Percentage \\
\hline Don't stress at all & 7 & 4.9 \\
\hline Stress a little & 51 & 35.4 \\
\hline Quite stress & 46 & 32.6 \\
\hline Very stressful & 39 & 27.1 \\
\hline
\end{tabular}

Table 3 illustrates that out of 144 students, there is four-level of stress among them. As shown, 7 students or $4.9 \%$ answered do not stress at all, 51 or $35.4 \%$ answered slightly stressed, 46 or $32.6 \%$ answered quite stressful, and 39 or $27.1 \%$ answered very stressful.

In addition, students provided reasons for the stress problems they encountered during online learning. Most of the reasons are in regard to the unsuitable environment and the unstable online learning system that makes learning boring. Some cannot focus and do not understand the lesson as they should. Some have health problems like headaches, eye strain, and muscle pain from sitting in front of the computer for too long. Furthermore, some students answer that having too many works is another cause of stress. Even so, some students shared the solution on how to fix the problems to study harder. Initially, create an inviting atmosphere, Secondly, exercise to rest the eyes, which including informing the teacher about the problem. Yet, there were some students who have encountered problems but still do not know how to solve them.

Table 4: Academic performance improved or worse

\begin{tabular}{|l|l|l|}
\hline Choice & Frequently & Percentage \\
\hline Better & 8 & 5.6 \\
\hline Regular & 68 & 47.2 \\
\hline Worse & 68 & 47.2 \\
\hline
\end{tabular}

Table 4 shows that Thai students in the Covid-19 situation have opinions about their academic performance during this pandemic situation. The number of regular grades that did not change was equal to the number of the reported declines in grades which is 68 . Whereas only 8 answered that it was better than last year.

Table 5: Is the online learning environment suitable?

\begin{tabular}{|l|l|l|}
\hline Choice & Frequently & Percentage \\
\hline Suitable & 81 & 56.3 \\
\hline Not suitable & 63 & 43.8 \\
\hline
\end{tabular}

Table 5 shows that out of 144 respondents, 81 students have a suitable home environment for online learning while 63 students do not have a suitable environment for studying due to different home factors. Examples of student reasoning include internet instability problems and the parents in the house called them to run errands during the course.

\section{DISCUSSION}

A research study of 144 students made us aware of problems affecting Thai students, both in an unconducive environment, online learning stressful situations, and the understanding of the students' lessons. Apparently, as a result of the research, most Thai students want to go back to onsite learning at school due to a lack of knowledge and understanding of online learning. Also, there are many problems that arise in online learning, especially stress. It is from the poor grades, the incomprehensibility of the lesson, and the environment that is not suitable for learning. Therefore, the government should solve the problem so that students can study as efficiently as possible. Moreover, the government should support learning for students to enhance learning development to be appropriate for the age range, including collaborating with the private sector to adjust the teaching style suitable for students, to reduce the stress that leads to problems such as depression and health problems.

\section{CONCLUSION}

In conclusion, this research is about the impact of the COVID-19 situation on Thai students; they used a quantitative questionnaire survey to collect the 
information from 144 Thai students in the lower secondary to the upper secondary level of the academic year 2021. Most students who answered the questionnaire have problems with the teaching system during the Covid 19 situation in terms of internet problems that impact learning, making them unable to study effectively enough, which affects the scores receivedcausing the score to be unsatisfactory, which is a factor that can lead to stress. Though, some Thai students solved their problems by trying to understand the lesson themselves. Moreover, some chose to discuss the problems they encountered with teachers. So how to solve the problems arising from the pandemic situation? The government must help and support students to learn effectively and not cause students stress and anxiety problems.

Acknowledgement: None

\section{Conflict of Interest: None}

\section{Source of Funding: None}

\section{REFERENCES}

1. Jiraporn Sricham. (28 March 2020). The days that Thai people know about COVID19. Thai PBS NEWS. Retrieved from https://news.thaipbs.or.th/content/290347

How to cite this article: Hongwisat $\mathrm{P}$, Wuthikanokkan T, Romayes C. How does COVID-19 affect Thai students?. International Journal of Research and Review. 2021; 8(9): 126-129. DOI: https://doi.org/10.52403/ijrr. 20210917

$* * * * * *$ 